\title{
Production of glycoalkaloids from callus cultures of Solanum hainanense Hance
}

\author{
Nguyen Hoang Loc $\cdot$ Nguyen Huu Thuan Anh $\cdot$ Doan Huu Nhat Binh $\cdot$ Moon-Sik Yang $\cdot$ Tae-Geum Kim
}

Received: 21 January 2010 / Accepted: 12 March 2010

(c) Korean Society for Plant Biotechnology

\begin{abstract}
Leaf explants of the Solanum hainanense plant, grown in vitro, were cultured in basal Murashige and Skoog (MS) media supplemented with $0.5 \mathrm{mg} / \mathrm{L}$ kinetin and $1 \mathrm{mg} / \mathrm{L}$ 2,4-dichlorophenoxyacetic acid (2,4-D) for callus initiation. For maintenance and proliferation, the callus was cultured on MS medium supplemented with $1 \mathrm{mg} / \mathrm{L}$ 6-benzylaminopurine (BAP) and $0.5 \mathrm{mg} / \mathrm{L}$ 2,4-D. The glycoalkaloid content in the callus was at its maximum after ten weeks of culture $(188.65 \mathrm{mg} / \mathrm{g})$, whereas that of the one-year-old control was $22.22 \mathrm{mg} / \mathrm{g}$ in the root and $5.99 \mathrm{mg} / \mathrm{g}$ in the stem. The glycoalkaloid extracted from the callus inhibited the activity of collagenase on collagen gel. High performance liquid chromatography (HPLC) analysis showed that biotransformation occurred when a callus was grown on medium supplemented with various carbon sources. These results suggest that callus of $S$. hainanense is a good material for production of glycoalkaloid.
\end{abstract}

Keywords Biotransformation, callus, glycoalkaloid, Solanum hainanense

\section{Introduction}

Glycoalkaloids have been found to inactivate the Herpes

Nguyen Hoang Loc · Nguyen Huu Thuan Anh •

Doan Huu Nhat Binh

(Institute of Resources, Environment and Biotechnology, Hue

University, Hue, Vietnam)

M.-S. Yang • T.-G. Kim ( ()

(Division of Biological Sciences and Research Center for

Bioactive Materials, Chonbuk National University,

Jeonju-Jeollabukdo 561-756, Republic of Korea)

e-mail: tgkim@jbnu.ac.kr

M.-S. Yang

(Jeonju Center for Korea Basic Science Institute, Chonbuk

National University, Jeonju 561-756, Republic of Korea) simplex, Herpes zoster, and Herpes genitalis viruses in humans (Chating et al. 1997), to protect mice against infection by Salmonella typhimurium (Gubarev et al. 1998), to enhance the duration of action of anesthetics which act by inhibiting acetylcholinesterase (McGehee et al. 2000), to lower cholesterol (Friedman et al. 2000a,b), and to serve as a malaria vaccine (Heal et al. 2001).

Solanum hainanense Hance plants accumulate glycoalkaloid primarily in their roots (Hop and Phuong 2003). Glycoalkaloids are secondary plant metabolites and are also known as phytoalexins (Stanker et al. 1996). Although they are reported to be potentially toxic, glycoalkaloids and their hydrolysis product without the carbohydrate side chain also have beeneficial effects. However, this plant has never been cultivated, and its various properties, including seasonal variation in growth and production of glycoalkaloid, are not yet known. Results of earlier experiments (Thu and Man 2000) revealed that total glycoalkaloid content per dry weight was less than $0.2 \%$ in the roots when this plant was grown in natural conditions.

Several papers have described the production of solasodine, a type of glycoalkaloid, in tissue cultures of Solanum laciniatum (Macek 1989) and Solanum nigrum (Yogananth et al. 2009). However, glycoalkaloid production in cultured tissue of Solanum species has not received much attention, and there have been a limited number of reports relating to the tissue culturing of $S$. hainanense (Anh et al. 2007). In general, however, plant cell and tissue cultures provide a potential means for studying the biosynthesis and accumulation of secondary metabolites in plants.

Therefore, the objective of this research was to determine the profile, distribution, and glycoalkaloid content in the calli of S. hainanense. 


\section{Materials and methods}

Plant materials

A leaf disc $(0.5 \times 0.5 \mathrm{~cm})$ was cultured on basal MS medium (Murashige and Skoog 1962) containing $30 \mathrm{~g} / \mathrm{L}$ sucrose and $8 \mathrm{~g} / \mathrm{L}$ agar, supplemented with $0.5 \mathrm{mg} / \mathrm{L}$ kinetin and 1.0 $\mathrm{mg} / \mathrm{L} 2,4-\mathrm{D}$ for callus induction. The callus was then cut into small pieces of $0.5 \mathrm{~cm}$ diameter for subculture in MS medium supplemented with $1.0 \mathrm{mg} / \mathrm{L} \mathrm{BAP}$ and $0.5 \mathrm{mg} / \mathrm{L} 2,4-\mathrm{D}$ for proliferation (Anh et al. 2007). The $\mathrm{pH}$ of the medium was adjusted to 5.8 before autoclaving. The effect of the various carbon sources was investigated by supplementing the medium with one of three sugars (fructose, glucose, and sucrose) at various levels from 20 to $40 \mathrm{~g} / \mathrm{L}$. All in vitro experiments were maintained at $25 \pm 2^{\circ} \mathrm{C}, 2000-3000$ lux and a photoperiod of 8-10 h/day.

Quantification of glycoalkaloid by HPLC

A callus of S. hainanense was dried at $35-50^{\circ} \mathrm{C}$ until it reached a constant weight, and then it was ground into a fine powder. Twenty grams of callus powder were pretreated for three h using a Soxhlet extractor (J.P. Selecta, Spain) with an acetic acid:methanol mixture $(5: 95, \mathrm{v} / \mathrm{v})$. The extract was then filtered and concentrated completely at $50^{\circ} \mathrm{C}$ using a vacuum rotary concentrator (Heidolph, Germany). The precipitate was dissolved in $10 \mathrm{~mL}$ methanol (glycoalkaloid extract) and filtered through Minisart $0.45 \mu \mathrm{m}$ membranes (Sartorius, Germany) in preparation for HPLC at ambient temperature with a Vertisep GES C18 column $(5 \mu \mathrm{m}, 4.6 \times$ $150 \mathrm{~mm}$ ). HPLC conditions were as follows: flow rate, 1 $\mathrm{mL} / \mathrm{min}$; run time, $10 \mathrm{~min}$; detector wavelength, $254 \mathrm{~nm}$; the stationary phase was silica gel (reverse phase) and the mobile phase consisted of $60 \%$ methanol. Twenty microliters of sample was injected into the column using a Hamilton syringe.

HPLC analysis was performed on a Spectra System apparatus (Thermo Electron Corporation, USA) using ChromQuest software (ver. 4.2.34). All solvents were of analytical grade and were purchased from Sigma and Merck \& Co., Inc.

Solasodine solution $(0.5 \mathrm{mg} / \mathrm{mL}$ in methanol) was used as a standard for determination of the total glycoalkaloid concentration $(\mathrm{X})$, and sample concentrations were calculated as follows:

$$
X=\frac{S_{M}}{S_{A S}} \times A \times 10
$$

where $S_{A S}$ is the peak area of the standard solasodine, $S_{M}$ is the peak area of the solasodine in the extract, $A$ is the concentration of the standard sample, and 10 is the dilution factor of the standard sample.

Determination of glycoalkaloid activity

Glycoalkaloid activity was determined based on collagenase activity using the method of Berman et al. (1973), with slight modifications. Collagenase activity was expressed in a sensitive capillary gel tube with a native collagen substrate by assessing the height of gel lysis after a given time.

Collagen type I from a mouse tail tendon was used as the substrate in the capillary gel assay and was purchased from Sigma (USA). Fifty milligrams of collagen was dissolved in $50 \mathrm{ml}$ of $0.05 \mathrm{M}$ acetic acid solution and titrated to $\mathrm{pH}$ 7.5-8.0 with $2 \mathrm{M}$ Tris base. Sufficient ice-cold $1 \mathrm{M} \mathrm{NaCl}$ was added to bring the solution to $0.4 \mathrm{M} \mathrm{NaCl}$. The solution was then dialyzed against $0.05 \mathrm{M}$ Tris $\mathrm{HCl}, 0.4 \mathrm{M} \mathrm{NaCl}\left(\mathrm{pH} 7.9,4^{\circ} \mathrm{C}\right)$, and any precipitate was removed by centrifugation. The collagen concentration in the supernatant was approximately $0.1 \%(1 \mathrm{mg} / \mathrm{mL})$.

Capillary tubes $(2 \times 150 \mathrm{~mm}$, open ended) were filled with approximately $150 \mu \mathrm{L}$ of collagen solution with a Hamilton syringe. After filling, the capillary tubes were sealed at the bottom with paraffin and were stood vertically in a box to gel overnight at $37^{\circ} \mathrm{C}$. Capillary gel tubes were then marked to indicate the height of the gel (determining the datum point of gel lysis).

A mixture of $0.2 \mathrm{mg} / \mathrm{mL}$ collagenase solution (type I, Sigma, USA) and glycoalkaloid solution from the callus of Solanum hainanense $(1: 1 \mathrm{v} / \mathrm{v})$ was added to the capillary gel tube. The height of mixture solution was $100 \mathrm{~mm} .0 .2 \mathrm{mg} / \mathrm{ml}$ collagenase solution was diluted to $0.1 \mathrm{mg} / \mathrm{mL}$ with $0.05 \mathrm{M}$ Tris $\mathrm{HCl}$ (pH 7.9). For the control, only $0.1 \mathrm{mg} / \mathrm{ml}$ collagenase solution was added without any glycoalkaloid solution. The capillary gel tube and control were incubated at $37^{\circ} \mathrm{C}$ for 24 $\mathrm{h}$. The height of gel lysis by collagenase was then measured to determine the activity of the glycoalkaloid extract.

Statistical analysis

The callus culture experiments were conducted with a minimum of three replicates. All experiments were repeated three times. The data were analyzed in terms of means \pm standard error followed by comparisons of the means using Duncan's tests using the SAS program (ver. 6.12). For all studies, the treatment groups were considered to be statistically significantly different from the controls at $p<0.05$. 


\section{Results and discussion}

Accumulation of glycoalkaloid in the callus

Glycoalkaloid was detected in all callus cultures obtained from $S$. hainanense. Fig. 1 illustrates the profiles of the glycoalkaloid accumulation as a function of culture time on the basal MS medium supplemented with $1 \mathrm{mg} / \mathrm{L} \mathrm{BAP}$ and $0.5 \mathrm{mg} / \mathrm{L}$ 2,4-D. Glycoalkaloid accumulation in vitro increased from weeks 2 to 10 and reached a maximum value of $188.65 \mathrm{mg} / \mathrm{g}$, whereas our study also showed that glycoalkaloid concentration in planta (one year old) was only $22.22 \mathrm{mg} / \mathrm{g}$ in the root and $5.99 \mathrm{mg} / \mathrm{g}$ in the stem. A Duncan's test (5\%) on the means confirmed that these samples were significantly different. These results indicate that callus is a suitable material for producing glycoalkaloid from $S$. hainanense.

Glycoalkaloid activity

Data in Table 1 shows that the length of the gel column in the test tube with glycoalkaloid from the calli had decreased to about 4.5 times less than that of the control $(15.0 / 67.7 \mathrm{~mm})$. Thus, the glycoalkaloid extract from the calli inhibited the activity of collagenase on the collagen. A similar obsevation was reported on total glycoalkaloid extract from the root of S. hainanense plant by Thu et al. (2000).

Effects of carbon source on callus growth and glycoalkaloid distribution

The callus growth and glycoalkaloid distribution under the effect of various carbon sources was investigated in seven-

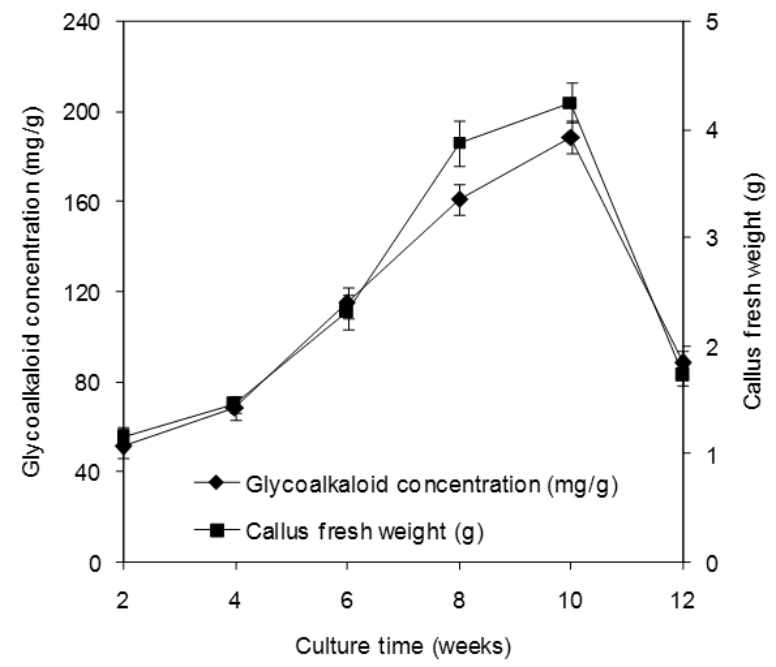

Fig. 1 Dynamics of callus growth and glycoalkaloid accumulation in S. hainanense weeks-old callus cultures. Our results showed that the highest callus fresh weight was attained in medium containing 30 $\mathrm{g} / \mathrm{L}$ sucrose (Table 2) and the eluted peaks of calli were more abundant than that of standard solasodine (Figs. 2, 3, 4 and 5). As shown in Fig. 2, the HPLC spectrum indicated that the solasodine produced two peaks at retention times of 2.09 and $2.27 \mathrm{~min}$; one of them was also detected in the calli grown on the media containing various concentrations of fructose,

Table 1 Glycoalkaloid activity analysis

\begin{tabular}{lcc}
\hline \multicolumn{1}{c}{ Test } & $\begin{array}{c}\text { Length of gel } \\
\text { column }(\mathrm{mm}) \\
\text { before treatment }\end{array}$ & $\begin{array}{c}\text { Length of gel } \\
\text { column }(\mathrm{mm}) \\
\text { after treatment }\end{array}$ \\
\hline $\begin{array}{l}\text { Control } \\
\begin{array}{l}\text { Glycoalkaloid of } \\
\text { callus }\end{array}\end{array}$ & 118.0 & $50.3^{\mathrm{b}}$ \\
\hline
\end{tabular}

Superscripts indicate significantly different means according to Duncan's test $(p<0.05)$.

Table 2 Effect of carbon source on callus growth and glycoalkaloid accumulation after 7 weeks of culture

\begin{tabular}{cccc}
\hline \multicolumn{2}{c}{ Sugar $(\mathrm{g} / \mathrm{L})$} & $\begin{array}{c}\text { Callus fresh weight } \\
(\mathrm{g})\end{array}$ & $\begin{array}{c}\text { Glycoalkaloid } \\
(\mathrm{mg} / \mathrm{g})\end{array}$ \\
\hline \multirow{4}{*}{ Fructose } & 20 & $0.82^{\mathrm{bc}}$ & $87.26^{\mathrm{c}}$ \\
& 30 & $1.11^{\mathrm{bc}}$ & $95.12^{\mathrm{bc}}$ \\
& 40 & $0.94^{\mathrm{bc}}$ & $86.73^{\mathrm{c}}$ \\
\hline \multirow{4}{*}{ Glucose } & 20 & $1.45^{\mathrm{b}}$ & $105.35^{\mathrm{b}}$ \\
& 30 & $1.52^{\mathrm{b}}$ & $107.93^{\mathrm{b}}$ \\
& 40 & $1.58^{\mathrm{b}}$ & $81.51^{\mathrm{c}}$ \\
\hline \multirow{4}{*}{ Sucrose } & 20 & $0.58^{\mathrm{c}}$ & $101.76^{\mathrm{b}}$ \\
& 30 & $2.89^{\mathrm{a}}$ & $128.17^{\mathrm{a}}$ \\
& 40 & $0.89^{\mathrm{bc}}$ & $93.60^{\mathrm{bc}}$ \\
\hline
\end{tabular}

Superscripts indicate significantly different means according to Duncan's test $(p<0.05)$.

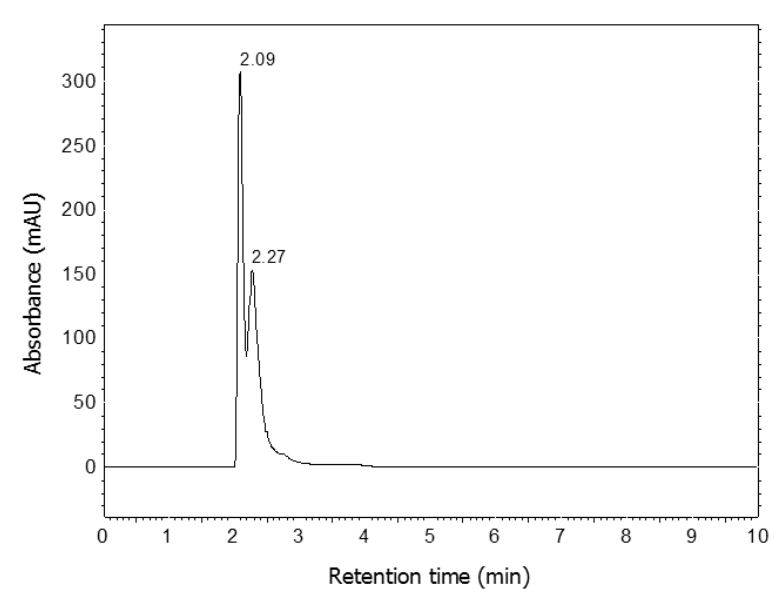

Fig. 2 HPLC chromatogram of standard solasodine $(0.5 \mathrm{mg} / \mathrm{mL})$ 

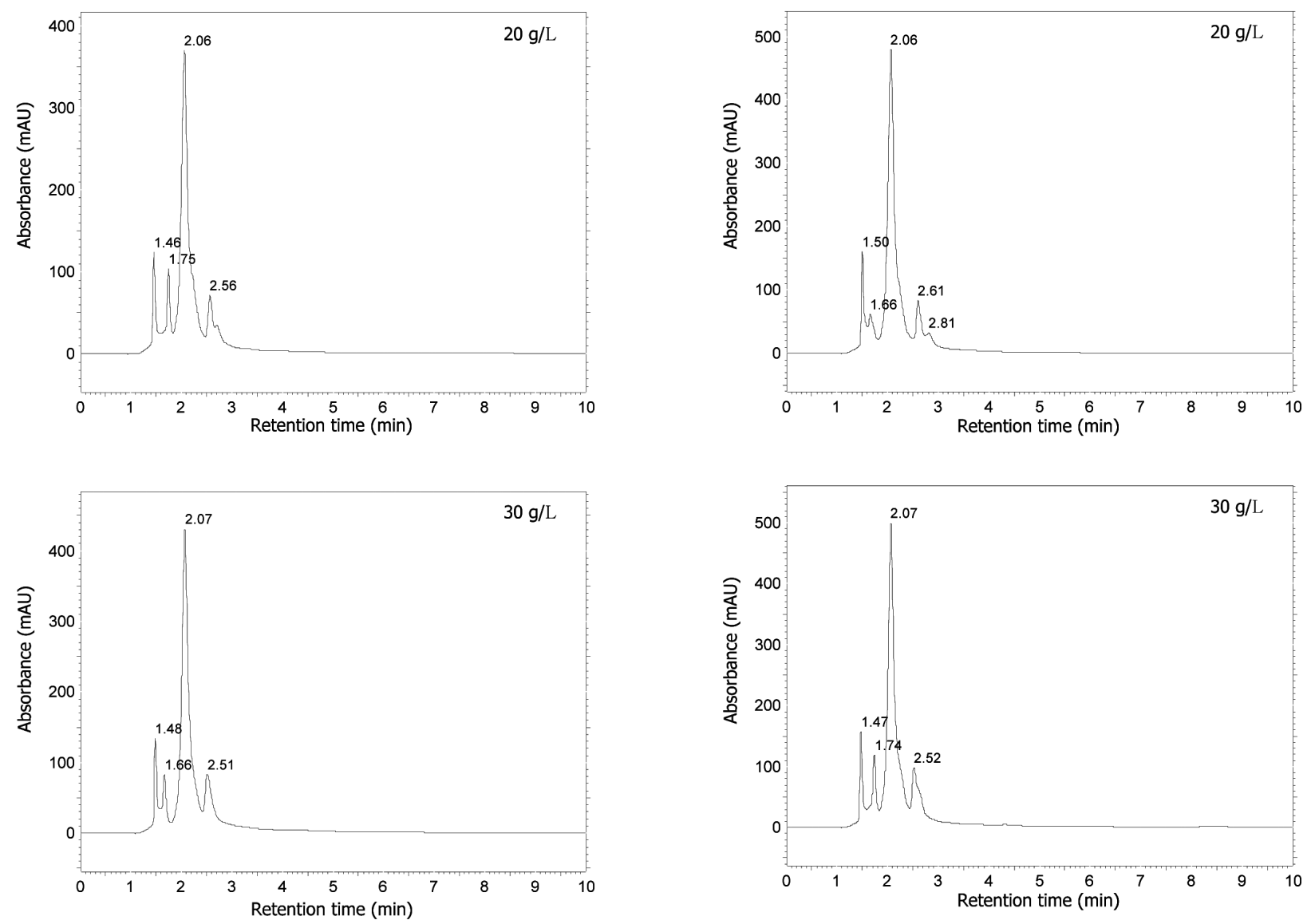

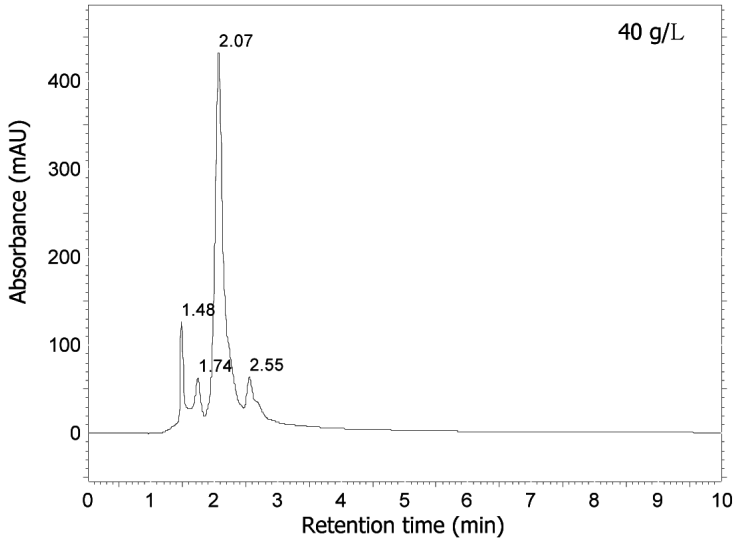

Fig. 3 HPLC chromatogram of the glycoalkaloid extract from a callus cultured on medium with fructose concentrations ranging from $20-40 \mathrm{~g} / \mathrm{L}$

glucose, and sucrose with the equivalent retention times of 2.06-2.07 min (Figs. 3, 4 and 5).

However, changes in the carbon source could also provide more diverse products by activation of alternate metabolic routes through a change in the carbon flux, therefore acting as an excellent tool for the study of plant cell metabolism (Rao et al. 2008). One of the possible reasons for this production of diverse products is a phenomenon called

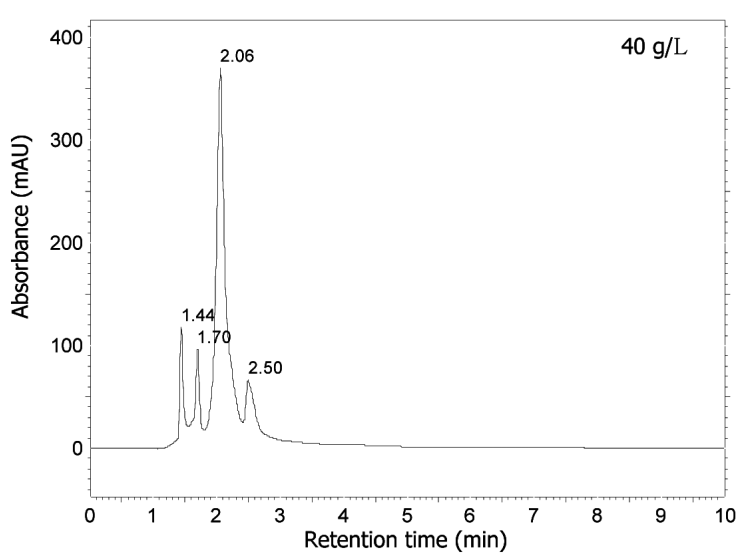

Fig. 4 HPLC chromatogram of the glycoalkaloid extract from a callus cultured on medium with glucose concentrations ranging from $20-40 \mathrm{~g} / \mathrm{L}$

somaclonal variation, commonly found in plant tissue culture, resulting in a high plant diversity as well as diverse secondary metabolite synthesis (Paska et al. 1999). Our results show that there were some small peaks with various retention times, other than the above-stated main peaks, occurring in callus cultures of $S$. hainanense.

Therefore, this observation may indicate that the cultures of $S$. hainanense calli produced glycoalkaloid. However, it is 

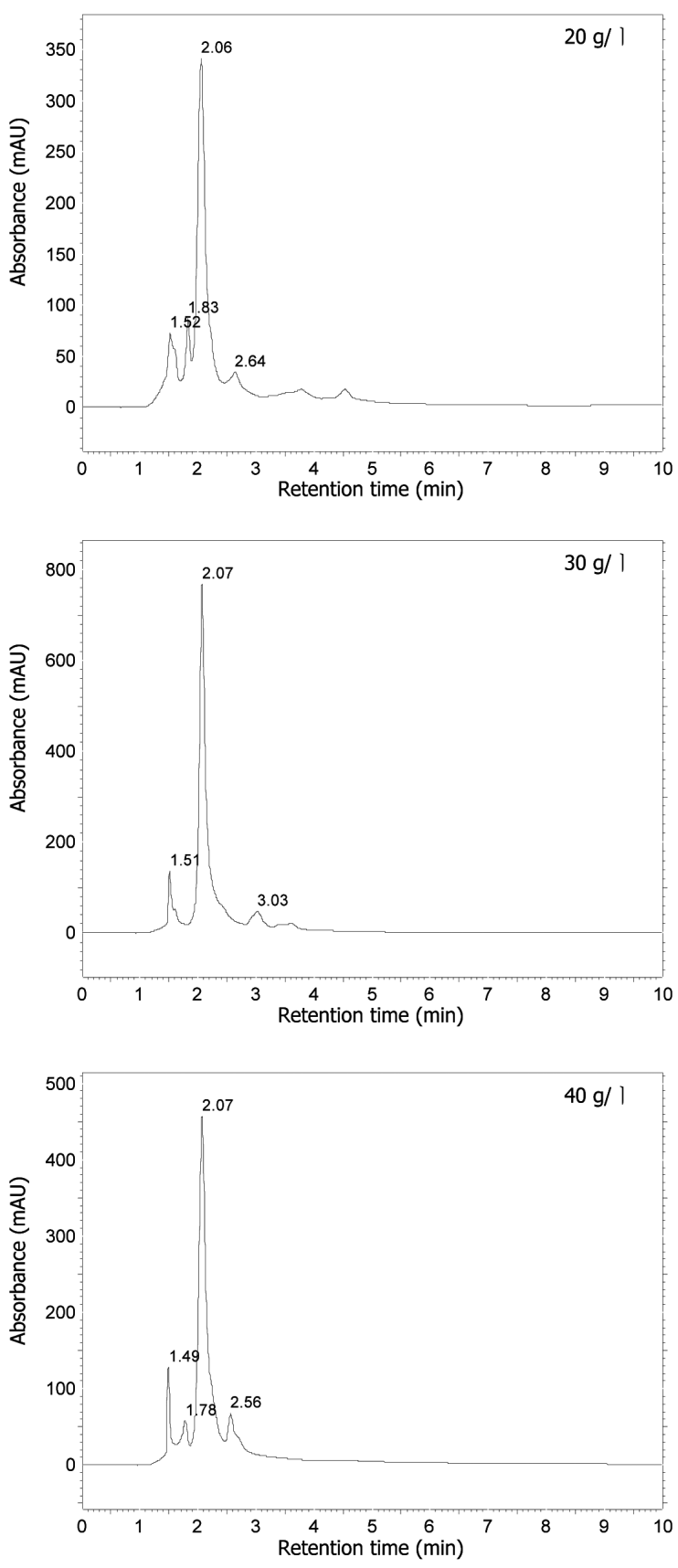

Fig. 5 HPLC chromatogram of the glycoalkaloid extract from a callus cultured on medium with sucrose concentrations ranging from $20-40 \mathrm{~g} / \mathrm{L}$

more likely that the biotransformation of glycoalkaloids appeared in calli which were cultured on media containing various carbon sources.

In addition, our results showed that glycoalkaloid content was the highest in the culture medium containing $30 \mathrm{~g} / \mathrm{L}$ sucrose (Table 2). When different carbon sources were tested for their influence on glycoalkaloid, sucrose supported good callus growth and glycoalkaloid accumulation, but fructose and glucose did not. These results indicated that sucrose is the most appropriate carbon source for glycoalkaloid production and this finding is similar to some other reports, including those describing the accumulation of lignan in callus of Impomoea batatas (Komaraiah et al. 2003), plumbagin in suspensions of Plumbago rosea (Jones and Veliky 1980), and berberine in cell cultures of Tinospora cordifolia (Subroto et al. 2007).

The results of this study indicate that the production of glycoalkaloid from calli of $S$. hainanense is possible. Although these results are promising, further studies should focus on the optimization of culturing conditions for the over-production of glycoalkaloid from $S$. hainanense.

\section{References}

Anh NHT, Thanh LTH, Binh DHN, Phuong TTB, Loc NH (2007) Study on the accumulation of glycoalkaloid in Solanum hainanense Hance callus. Proc the 2007th National Conference on Life Sciences. Sci and Tech Publishing House, Hanoi, Vietnam, pp. 229-232

Berman MB, Manabe R, Davison PF (1973) Tissue collagenase: A simplified, semiquantitative enzyme assay. Anal Biochem 54: 522-534

Chating B, Conepcion L, de Cristancho B, Usubillaga A (1997) Estudio clinico de la efectividad de extractos alcaloides optenidos de los frutos del Solanum americanum Miller sorbe el Herpes simplex, Herpes zoster y Herpes genitalis. Revista de la Facultad de Farmacia 32:18-25

Friedman M, Fitch TE, Levin CE, Yokoyama WH(2000a) Feeding tomatoes to hamsters reduces their plasma low-density lipoprotein cholesterol and triglycerides. J Food Sci 65:897-900

Friedman M, Fitch TE, Yokoyama WH (2000b) Lowering of plasma LDL cholesterol in hamsters by the tomato glycoalkaloid tomatine. Food Chem Toxicol 38:549-553

Gubarev MI, Enioutina EY, Taylor JL, Visic DM, Daynes RA (1998) Plant-derived glycoalkaloids protect mice against lethal infection with Salmonella typhimurium. Phytother Res $12: 79-88$

Heal KG, Sheikh NA, Hollingdale MR, Morrow WJW, TaylorRobinson AW (2001) Potentiation by a novel alkaloid glycoside adjuvant of a protective cytotoxic $\mathrm{T}$ cell immune response specific for a preerythrocytic malaria vaccine candidate antigen. Vaccine 19:4153-4161

Hop VV, Phuong VX (2003) Alkaloid species belong to Solanaceae family in Vietnam. J Biol 25:27-31 (in Vietnamese)

Jones A, Veliky IA (1980) Growth of plant cell suspension cultures on glycerol as a sole source of carbon and energy. Canadian J Bot 58:648-657

Komaraiah P, Ramakrishna SV, Reddanna P, Kavi Kishor PB (2003) Enhanced production of plumbagin in immobilized cells of Plumbago rosea by elicitation and in situ adsorption. 
J Biotechnol 101:181-187

Macek TE (1989) Solanum aviculare Forst., Solanum laciniatum Ait: In vitro culture and the production of solasodine. In: Bajaj YPS (ed) Biotechnology in Agriculture and Forestry. Springer Verlag, Berlin Heidelberg. Vol 7, pp 443-463

McGehee S, Kraswoski D, Fung L (2000) Cholinesterase inhibition by potato glycoalkaloids slows mivacurium metabolism. Anesestesiol 93:510-519

Murashige T, Skoog F (1962) A revised medium for rapid growth and bioassays with tobacco tissue cultures. Physiol Plant 15: 473-497

Paska C, Innocenti G, Kunavari M, Laszio M, Szilagyi L (1999) Lignan production by Ipomoea batatas callus cultures. Phytochem 52:879-883

Rao RB, Kumar DV, Amrutha RN, Jalaja N, Vaidyanath K, Rao AM, Rao S, Polavarapu R, Kishor PBK (2008) Effect of growth regulators, carbon source and cell aggregate size on berberine production from cell cultures of Tinospora cordifolia Miers. Curr Trends Biotechnol Pharm 2:269-276
Subroto MA, Tampubolon E, Simanjuntak P (2007) Changes in solasodine accumulation in regenerated plants of Solanum nigrum transformed with Agrobacterium rhizogenes 15834. Biotechnol 6:328-333

Stanker LH, Kampos-Holtzapple C, Beier RC, Levin CE, Friedman M (1996) Detection and quantification of glycoalkaloidscomparison of enzyme-linked immunosorbent assay and high-performance liquid chromatography methods. ACS Symp Ser 621:243-251

Thu NB, Khai NM, Man PK, Nhu DT (2000) Effects of Solanum hainanense Hance on collagenase. J Pharm Materials 5:149 -152 (in Vietnamese)

Thu NB, Man PK (2000) Quantitative determination of glycoalkaloids in Solanum hainanense Hance by acid dye colorimetric method. J Pharm Materials 5:104-108 (in Vietnamese)

Yogananth N, Bhakyaraj R, Chanthuru A, Parvathi S, Palanivel S (2009) Comparative analysis of solasodine from in vitro and in vivo cultures of Solanum nigrum Linn. Kathmandu Univ J Sci Engin Technol 5:99-103 